$\underline{\text { Original Article }}$

\title{
IMPACT OF CLINICAL PHARMACY SERVICES IN GENERAL SURGERY
}

\author{
PRADEEP BATTULA ${ }^{1 *}$, B. TEJASWINI², M. AKHILA REDDY², M. P. HAREEN SHANKAR², T. SAI YASHODA \\ KRISHNA $^{2}$, V. BRAHMA REDDY 3
}

1Department of Pharmacy Practice, Sri Padmavathi School of Pharmacy, Tirupati, Andhra Pradesh, India, ${ }^{2}$ Department of Pharmacy Practice, Creative Educational Society's College of Pharmacy, Chinnatekur, Kurnool, Andhra Pradesh, India, ${ }^{3}$ Superintendent, Dr. V. Brahma Reddy Hospital, Hernia and SUI Center, Kurnool, Andhra Pradesh, India

Email: doctorbattulapradeep@gmail.com

Received: 05 Nov 2019, Revised and Accepted: 07 Mar 2020

\begin{abstract}
Objective: The objectives of this study include performing pharmaceutical care-related research and documenting regarding drug-related problems in the surgery department. Further, these types of studies may bring consciousness to both physicians and patients regarding drug use in surgery.

Methods: A Prospective interventional study was conducted in a general surgery hospital. The prescriptions were analyzed for the use of inappropriateness of drugs using the classification for drug-related problems.

Results: Out of 100 cases, 62 patients were observed with drug-related problems. The number of antibiotics prescribed was 0, 1, 2, 3, 4, 5, 6 in 8, 11, $12,32,18,18,1$ cases respectively. A significant increase in the outcome of antibiotic rationality and cases adhered to guidelines was seen in November compared to October and somewhat decreased in December due to some limitations. The overall study states that prescribing has a more
\end{abstract} important cause of Drug-related problems compared to dispensing and the use of the drug.

Conclusion: Drug-related problems have to be acknowledged as a very important contributing treatment factor for the best health care outcome. Our study shows the importance of clinical pharmacists in every hospital for identifying and resolving drug-related problems and medication errors.

Keywords: Clinical pharmacist, Drug-related problems, Medication errors, Antibiotic rationality, Pharmaceutical care

(C) 2020 The Authors. Published by Innovare Academic Sciences Pvt Ltd. This is an open access article under the CC BY license (http://creativecommons.org/licenses/by/4.0/) DOI: http://dx.doi.org/10.22159/ijpps.2020v12i4.36283. Journal homepage: https://innovareacademics.in/journals/index.php/ijpps

\section{INTRODUCTION}

Medications play a major role in cure palliation and inhibition of disease; they also expose patients to Drug-Related Problems (DRPs) [1]. The definition includes that according to Pharmaceutical Care Network Europe Foundation, drug-related problems are defined as "a drug-related problem is an event or circumstance involving drug therapy that actually or potentially interferes with desired health outcomes." An actual problem has related to clinical manifestations like Adverse Drug Reactions or Therapy failure due to incorrect dosage. A potential problem is not manifest, but if left unresolved it may lead to drug-related harm to patients [2]. The critical issue in the present world's DRPs is that the practice of self-medication is common in India and other major parts of the world which is associated with a higher risk of various DRPs [3]. Confusion over multiple medications or complex medication regimens and poor counseling by health care professionals can lead to DRPs [4]. Generally, female sex, polypharmacy, renal impairment, co-morbid medical conditions, concomitant medications, nonconformity to standard established guidelines, lack of proper laboratory and therapeutic drug monitoring, pharmacogenetic variations, medication errors, patient-related factors, age over $65 \mathrm{y}$ and use of narrow therapeutic index drugs were identified as risk factors for DRPs [5]. Even though, physicians and nurses, who provide support for better quality outcomes of patients there is a lack of different health care professionals on this issue whether pharmacist manages drug therapy as equivalent to physicians [6]. The patient is unable to recognize the actual adverse effect of the drug. We may not know the actual level of drug in the body, renal function, adherence to medications and accuracy of drug used and dispensed [7]. In India many factors contribute to DRPs, of these factors related to health care providers are misuse medications in prescribing practices, time constraints, diagnostic uncertainty, poor availability of laboratories. Use of more expensive medications given despite them not being the most appropriate choice when it comes to antibiotic misuse it was noted that private practitioners ted to use more expensive antibiotics than rural practitioners. In hospitals, one of every 130 admitted patients dies with adverse effects. In this, nearly 80 inpatients events are involved in surgical treatment. So we in our research aimed at clinical pharmacist services in the surgical ward [8]. Clinical pharmacy interventions could also decrease the cost of treatment. The main need is to enhance the role of clinical pharmacy services in the hospital which influences the patient's health care in a positive outcome. The main aim of this study is to perform pharmaceutical care-related research and document regarding medical errors and drug-related problems in surgery. Further, these types of studies may bring consciousness to both physicians and patients regarding drug use in surgery.

\section{MATERIALS AND METHODS}

A hospital-based Prospective interventional study was conducted in the Hernia and SUI Centre. It was an out-patient and in-patients based private hospital. The patients from various places visit this hospital for treatment of these specified diseases and related complications. The study was conducted for a period of 6 mo from August 2018 to January 2019, after obtaining permission from the institution; this permission was sanctioned by an institutional ethics committee. We collected 100 prescriptions during this period. Patients were enrolled in the study based on inclusion and exclusion criteria. We included patients who were diagnosed with a hernia, hysterectomy, appendectomy and minor surgeries, Patients who were under the surgical therapy; either gender was considered who were below $70 \mathrm{y}$ and who were coming for regular follow-up. We excluded patients who were admitted to the hospital and not undergone surgery. The study team was collected the needed information regularly; the purpose of the study was explained in detail to the study population and obtained consent. This consent was proposed through an informed consent form. The source of data was obtained from Patient case files, by interacting with the patient and patient representative and laboratory findings. All the collected data was included in a specially designed proforma, which includes patient demographics, past medical history, family and surgical history, co-morbidities, diagnosis and present medications 
prescribed for each patient. Total of 100 cases was collected from surgical wards, according to study criteria. All the prescriptions which contain different drugs were included in the study. All the prescriptions were analyzed for inappropriateness use of drugs and drug-related problems.

\section{Statistical analysis}

All the data were entered and performed in Microsoft Excel 2007 version. Mean, percentages used where required. To obtain statistical significance T-test: two-sample assuming unequal variances test was chosen. P-value $<0.05$ considered as significant.

\section{RESULTS}

In our study, a total of about 100 study participates were included among them about $61 \%$ were females and $31 \%$ were males. There are 3 patients between the age group of $0-10 \mathrm{y}, 6$ patients between the age group of 11-20 y, 40 patients between the age group of 21$30 \mathrm{y}, 20$ patients between the age group of 31-40 y, 7 patients between the age group of $41-50 \mathrm{y}, 12$ patients between the age group of 51-60 y and 12 patients between the age group of 61-70 y. Table 1 showed that among 100 patients 62 patients were having drug-related problems and the remaining 39 patients do not have drug-related problems in their prescription, the overall distribution of problems between 62 patients. The problems were categorized into three types, which include therapy effectiveness, therapy safety, and others. Among 62 patients 2 patients come under therapy effectiveness, 1 patient comes under therapy safety and the remaining 58 patients come under others. In the same way table 1 showed that over 6 mo of study we were observed the causes of DRPs with drug choice were found to be more and it was about 54 and the drug use process was 16 respectively. The overall study states that prescribing was a more important cause of DRP compared to dispensing and utilization of the drug. Acceptance and implementation of intervention it says that there were 13 cases whose intervention was accepted and fully implemented, 6 cases whose intervention was accepted and not implemented, 3 cases whose intervention was accepted but implementation was unknown, 2 cases whose intervention was proposed but acceptance was unknown and one case whose intervention was accepted and partially implemented. There were 36 cases whose intervention was not proposed as there was no possibility. The status of DRP in 100 cases like a problem not solved was 38 , partially solved were 6 , status unknown were 4 , totally solved were 13 , cases without DRPs were 39. There were 69 cases with medication errors and they were of different types. In 69 cases, the majority of errors are due to prescribing error and poor handwriting which accounts for 23 cases. Only prescribing error accounts for 20 cases, there were 16 cases with prescribing error and poor handwriting and spelling mistake. Only poor handwriting accounts for 7 cases. Remaining errors like wrong duration error, wrong drug administration technique and wrong drug error account for 1 case each. There were 31 cases with no errors. The information stated in table 1 and table 2 , states that overall statistics of cases in the month of October total number of cases were 40 in which rationality not followed in 20 cases. Cases adhered to guidelines were 13 and cases without DRPs were 11 . In November out of 36 cases rationality was followed in 21 cases, not followed were 15, cases adhered to guidelines were 21 and cases without DRPs were 18 . In December out of 24 cases rationality were followed in 13 cases, not followed were 11, cases adhered to guidelines were 12 and cases without DRPs were 10. and fig. 1 explains that in the month of October $50 \%$ of cases followed antibiotic rationality and $32.50 \%$ of cases adhered to guidelines out of 40 cases. In November month $58.30 \%$ of cases followed antibiotic rationality and $58.33 \%$ of cases adhered to guidelines out of 36 cases. In December month $54.16 \%$ of cases followed antibiotic rationality and $50 \%$ of cases adhered to guidelines out of 24 cases.

Table 1: Details of pharmacist intervention in surgery

\begin{tabular}{|c|c|c|c|}
\hline \multirow[t]{2}{*}{ Variables } & \multicolumn{2}{|c|}{ Number of cases } & \multirow[t]{2}{*}{ P-Value } \\
\hline & Male & Female & \\
\hline \multicolumn{4}{|l|}{ Drug-related problems } \\
\hline Yes & 24 & 37 & \multirow[t]{2}{*}{0.29} \\
\hline No & 15 & 24 & \\
\hline \multicolumn{4}{|l|}{ Type of problem } \\
\hline Therapy Effectiveness & 2 & 0 & \multirow[t]{3}{*}{0.77} \\
\hline Therapy Safety & 0 & 1 & \\
\hline Others & 22 & 36 & \\
\hline \multicolumn{4}{|l|}{ Causes of DRPs } \\
\hline Drug choice & 20 & 34 & \multirow[t]{8}{*}{0.68} \\
\hline Drug Form & 0 & 0 & \\
\hline Dose Selection & 1 & 2 & \\
\hline Therapy Duration & 1 & 0 & \\
\hline Dispensing & 0 & 0 & \\
\hline Drug Utilization Process & 6 & 10 & \\
\hline Patient-Related & 2 & 1 & \\
\hline Other & 1 & 0 & \\
\hline \multicolumn{4}{|l|}{ Acceptance and implementation of an intervention } \\
\hline Intervention not proposed & 17 & 19 & \multirow[t]{7}{*}{0.53} \\
\hline Intervention accepted and fully implemented & 5 & 8 & \\
\hline Intervention accepted and partially implemented & 0 & 1 & \\
\hline Intervention accepted but not implemented & 1 & 5 & \\
\hline Intervention accepted, implementation unknown & 2 & 1 & \\
\hline The intervention proposed, acceptance unknown & 0 & 2 & \\
\hline Cases without DRPs & 15 & 24 & \\
\hline \multicolumn{4}{|l|}{ Status of DRP } \\
\hline Problem Not Solved & 17 & 21 & \multirow[t]{5}{*}{0.44} \\
\hline Partially Solved & 1 & 5 & \\
\hline Unknown & 2 & 2 & \\
\hline Totally Solved & 4 & 9 & \\
\hline No DRP Cases & 15 & 24 & \\
\hline \multicolumn{4}{|l|}{ Type of medication error } \\
\hline Poor Handwriting & 3 & 4 & \multirow[t]{8}{*}{0.41} \\
\hline Prescribing Error & 4 & 16 & \\
\hline Prescribing Error and Poor Handwriting & 10 & 13 & \\
\hline Prescribing Error and Poor Handwriting, spelling mistake & 10 & 6 & \\
\hline Wrong Drug Error & 1 & 0 & \\
\hline Wrong Drug Administration Technique & 1 & 0 & \\
\hline Wrong Duration Error & 0 & 1 & \\
\hline No Errors & 10 & 21 & \\
\hline
\end{tabular}


Table 2: Overall statistics of cases

\begin{tabular}{llllll}
\hline Month & Total cases & Rationality followed & Rationality not followed & Cases with DRPs & Cases with adherence to guidelines \\
\hline October & 40 & 20 & 20 & 11 & 13 \\
November & 36 & 21 & 15 & 18 & 21 \\
December & 24 & 13 & 11 & 20 & 12 \\
Total & $\mathbf{1 0 0}$ & $\mathbf{5 4}$ & $\mathbf{4 6}$ & $\mathbf{4 9}$ & $\mathbf{4 6}$ \\
\hline
\end{tabular}

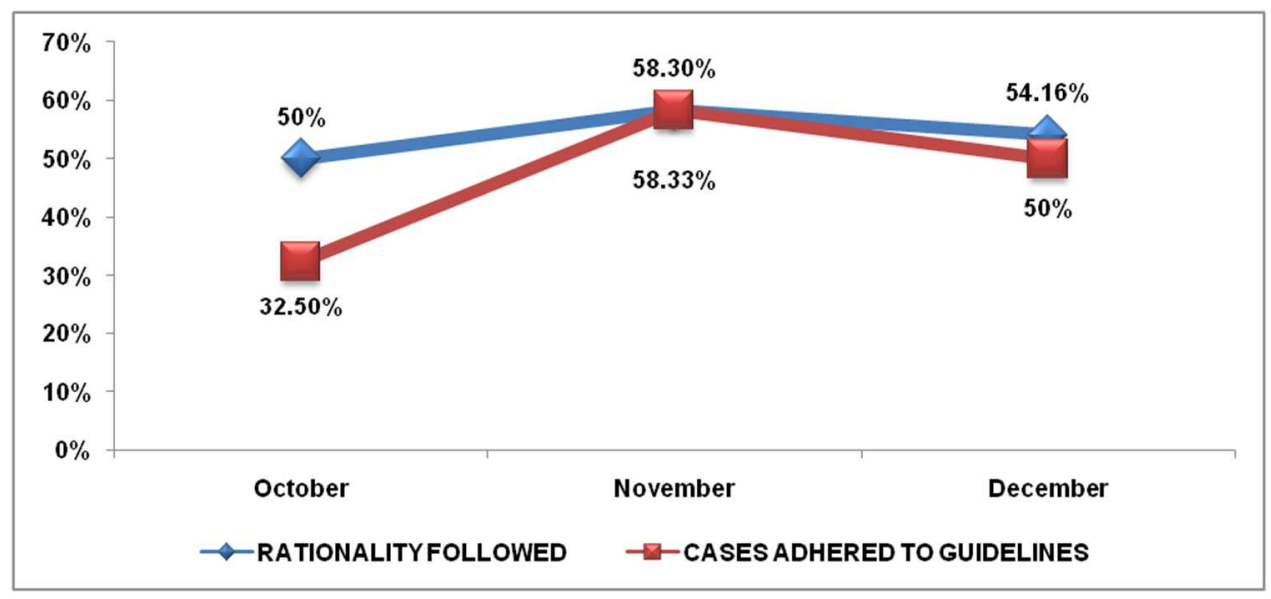

Fig. 1: Rationality of cases during the observation

\section{DISCUSSION}

The study, we started with a question of what is the need of clinical pharmacy and about its concept. To get the answer to our question, we provided clinical pharmacy services up to our study period to observe a respective outcome. From day one, we have reviewed the cases and observed the treatment chart of patients. Gradually we found so many errors like improper drug chart maintenance and patient vitals, medication errors, Drug-Related Problems. By observing case report forms we found that problems occurred because of the improper prescribing pattern. Statistics of present surgical conditions in hospitals one of every 130 admitted patients die with adverse effects. In these nearly 80 inpatients events are involved in surgical treatment. So we in our research aimed at clinical pharmacist services in the surgical ward [9]. As clinical pharmacists, we made discussions with the prescriber and resolved the problem. As there is no time to verify the authenticity of the information of the case sheet for doctor our clinical pharmacists are much helpful. Due to our presence and counseling, some of the patients got assured and believed us as their caretakers. Our primary objective is to assess DRPs. To make our structured analysis possible, the Classification for drug-related problems code order was used as a guide to assess DRPs. We have analyzed and documented 100 cases in which we found 61 Patients with DRPs. The problems of these DRPs are no effect of drug treatment, adverse drug events occurring, the problem with the cost-effectiveness of the treatment, unnecessary drug treatment. An ADR is defined according to the World Health Organization (WHO) as any response to a drug which is noxious and unintended, and which occurs at doses normally used in man for prophylaxis, diagnosis, or therapy of disease, or for the modification of physiological function [10]. Classification of drug-related problems is widely used because here the professional himself decides what the actual problem is whereas in other systems patient decides the problem along with professional to some extent. As patients don't have enough knowledge on DRPs they are only taken as a source of information but not in decision making. By this system, it is easy for both the clinical pharmacist and medical professional in intervening the DRPs $[11,12]$. Among these problems, unnecessary drug treatment accounts for a major percentage (95.08\%). The above problems are caused due to drug selection (54\%), drug form $(0 \%)$, dose selection $(3 \%)$, treatment duration $(1 \%)$, dispensing $(0 \%)$, drug use process $(16 \%)$, patient-related $(3 \%)$,other $(1 \%)$. The supportive nature of the chief doctor, our interventions regarding errors were quickly accepted and implemented. The chief doctor encouraged us to involve in prescription auditing to find, report and document any prescribing errors by duty doctors and administrating errors by nurses. Many intentional and non-intentional patient-related errors have been reported to the chief doctor, who was resolved by him instantly with appreciation. In comparison with A. Chandrakanth et $a l$. the study they have concluded that of a total of 250 subjects in general medicine the most common DRP found was drug-drug interactions accounting for $75.97 \%$. But in our study with 100 subjects in general surgery, we have seen major DRP as unnecessary drug treatment accounting of $95.05 \%$ [2]. Movva et al., the study states that DRPs caused due to improper drug selection were found to be highest which accounts for $22.17 \%$ and an acceptance rate of clinical pharmacist recommendations is $62.8 \%$ and change in drug therapy was found to be low.1.68\% were neither accepted nor the therapy was changed, [4] but in our study shows that DRPs caused due to improper drug selection accounts for $54 \%$ and all the interventions made are accepted. In $43 \%$ of the cases, the therapy has been changed. An effective ADR monitoring program has the following 4 features: A clearly defined guideline of reportable ADR, A concurrent method of monitoring and reporting adverse drug events, A proper system of reviewing, A feedback to incorporate changes in system health delivery system with a view to their prevention [13]. Factors responsible for drug interaction: Insufficient knowledge, Dietary factors, Physiology of the individual, Presence of disease states [14]. Our study defines that the mean duration of hospital stay was three days which led to less cost burden to patients. Prior to our intervention hospital staff used to follow an inappropriate class of antibiotics, irregular administration timings and dosing intervals of IV fluids, NSAIDs. We have observed and reported all these interventions to the chief doctor. Later he accepted our interventions and proposed to follow a set of guidelines based on the surgical procedure to administration staff and divided them into four categories as Clean cases (thyroidectomy, herniotomy, lipoma, tubectomy), Clean but potentially contaminated (chronic appendicitis, hysterectomy, fissures, piles), Contaminated (roadside injuries, infected surgeries), Grossly contaminated (peritonitis, septicemia, scab injuries). The chief doctor practically considered category 1 and 2 into one group and categories 3 and 4 into another group and proposed respective rationalized treatment. Initially, rationalization to treatment was strictly followed and we observed a decline in DRPs. The cases with no DRPs was seen with 
$27.50 \%$ in our first month which was later increased to $50 \%$ with the active involvement of hospital staff and clinical pharmacist, later the percentage decreased to $41.60 \%$ in the third month due to some limitations. Moreover, the majority of interventions and proposals made by the clinical pharmacist were accepted. Though the concept of pharmacotherapy and profession of clinical pharmacy services are new to nursing staff and duty doctors, they showed interest and suggested us to involve in more of patient-related activities which help to increase their queries on drugs. Our diligence in the profession was admired by them which ultimately reflected the importance of our presence in the healthcare team. With the trust in our proposed interventions chief doctor granted to audit prescription pattern thoroughly and advised us to authenticate the administration techniques of IV fluids, usage of appropriate drug selection to diagnosis, time of drug administration and to solve other pharmaceutical-related issues. The limitations of our study were, the exposure to cases was less within our study period. Change in administration staff resulted in repeated counselling to them which were not followed to the full extent which led to an increase in cases with DRPs. There was no possibility to discuss each and every intervention with the chief doctor due to his busy schedule in the profession. The above all factors made our interventions were not solved or partially solved. During this step, the main aim is to provide the boundaries and terms of reference for the treatment of antibiotics in surgery for a minimal number of days with fewer side effects. The future scope of this type of study can be strengthened by minimizing the gap between the doctor, and a clinical pharmacist. The biggest challenge to make this type of outcome come to reality is to create a skilled workforce that is equipped to deal with the issues pertaining to the healthcare industry. The efficient operation of the implementation of the work by tracking all the day to day activities and records of the patient and providing satisfactory service to the patients are the major strength of our study. In India, there are very limited studies and less documentation of records of drug-related problems. As India is one of the highest populated countries with diversified customs health care related topics and studies should be focused on strong determination. Population has been also taking drugs in pharmacies without prescription, which has chances to increase in DRPs [15]. In this research we were also observed inappropriate utilization of antibiotics; this also very serious issue may causes to bacterial resistance according to Herawati et al. [16]. Clinical pharmacy, a new recent trend of health care sector which mainly focus on patient-related aspects, when implemented in every hospital can improve patient quality in both cost and treatment effectiveness. This when done properly, can improve drug-related problems, which anticipate drug mortality, drug morbidity, patient safety and adherence to the rationality of drug treatment. Awareness about of usage of drugs and its outcomes can only be done by pharmacovigilance centers when established in the hospital sector where again clinical pharmacist plays a key role. Developing patient counseling centers in every hospital can also improve inpatient prescription auditing, advising them regarding drug knowledge which benefits patients.

\section{CONCLUSION}

We conclude that the Drug-related problems have to be acknowledged as a very important contributing treatment factor for best health care outcome. Our study shows the importance of clinical pharmacists in every hospital for identifying and resolving drugrelated problems, medication errors. This helps in improving better patient care. Moreover, the interventions proposed are well accepted by the physician. The pharmacist should play a major role in the prevention of various drug-related problems by pharmaceutical activities through their involvement in the health care team. This shows the importance of Clinical pharmacists in developing countries like India.

\section{ABBREVIATIONS}

SUI center: Surgical urinary incontinence, DRPs: Drug-related problems

\section{FUNDING}

Nil

\section{AUTHORS CONTRIBUTIONS}

All the authors have contributed equally for the completion of this research.

\section{CONFLICT OF INTERESTS}

The authors declare no conflict of interest regarding the content of this article.

\section{REFERENCES}

1. Mekonnen GB, Birarra MK, Tekle MT, Bhagavathula AS Assessment of drug-related problems and its associated factors among medical ward patients in University of Gondar teaching hospital, northwest Ethiopia: a prospective cross-sectional study. J Basic Clin Pharm 2017;8:16-21.

2. Chandrakanth. Impact of a clinical pharmacist on drug-related problems. Indo Am J Pharm Res 2015;5:3816-21.

3. Pandaa, Pradhans, Mohapatra G, Mohapatra J. Drug-related problems associated with self-medication and medication guided by prescription: a pharmacy-based survey. Indian J Pharmacol 2016;48:515-21.

4. Movvar, Jampania, Nathani J, Pinnamaneni SH, Challa SR. A prospective study of the incidence of medication-related problems in the general medicine ward of a tertiary care hospital. J Adv Pharm Technol Res 2015;6:190-4.

5. Iyer K, Dilipkumar N, Vasaya S, Pawar S, Diwan A. Comparison of drug-related problems associated with the use of narrow therapeutic index drugs and other drugs in hospitalized patients. J Young Pharm 2018;10:318-21.

6. Kirsten K Viktil, Hege Salvesen Blix. The impact of clinical pharmacists on drug-related problems and clinical outcomes. Basic Clin Pharmacol Toxicol 2008;102:275-80.

7. Sepehri. Potential drug interactions in an Iranian general hospital. Indian J Pharm Sci 2012;74:75-9.

8. De Boer M, Ramrattan MA, Boeker EB, Kuks PFM, Boermeester MA, Lie-A-Huen L. Quality of pharmaceutical care in surgical patients. Plos One 2014;9:e101573.

9. S balasubramanian, N Narayanan. Hospital and clinical pharmacy. 2nd edition. Pharmamed Press: Hyderabad; 2013. p. 190-4.

10. Chris J Bonner, Bruce Carr. Medication compliance problems in general practice: detection and intervention by pharmacists and doctors. Australian J Rural Health 2002;10:33-8.

11. Ingeborg K, Bjo Rkman, Margareta A Sanner, Cecilia B Bernsten. Comparing 4 classification systems for drug-related problems: processes and functions. Res Soc Administrative Pharm 2008;4:320-31.

12. Roshanzamiri S, Eslami K, Najmeddin F, Izadpanah M, Hadidi E, Ganji R. Validating a drug-related problem classification system in an outpatient setting in Iran. J Res Pharm Practice 2018;7:117-22.

13. http://www.thecabinchianmai.com/blog/countries-withworst-drug-related-problems / [Last accessed on 02 Oct 2018]

14. Gillian Porter, Nathan Grills. Medication misuse in India: a major public health issue in India. J Public Health 2016;3:150-7.

15. Varghese Sneha Suja, Sneha Dutta, Ann Mary Swaroop. Knowledge and perceptions of self-medication practices in an urban community. Asian J Pharm Clin Res 2019;12:42-5.

16. Fauna Herawati, Muhamad Satria Mandala Pua Upa, Rika Yulia, Retnosari Andrajati. Antibiotic consumption at a pediatric ward at a public hospital in Indonesia. Asian J Pharm Clin Res 2019;12:64-7. 